\title{
Examination of hysterosalpingography in patients with suspected infertility at the radiology department of Dr.R. Soetrasno Rembang Hospital
}

\author{
Retno Wati ${ }^{*}$, Siti Masrochah ${ }^{2}$ \\ ${ }^{1}$ Department of Radiology, Faculty of Health Sciences, Universitas 'Aisyiyah Yogyakarta, Ring Road Barat Street \\ No.63 Sleman, Yogyakarta 55292, Indonesia \\ ${ }^{2}$ Health Polytechnics of Semarang, Indonesia \\ ${ }^{1}$ wati.retno@unisayogya.ac.id*, masrochah2@gmail.com \\ * corresponding author
}

Submission date: 6 September 2021, Receipt date: 8 Oktober 2021, Publication date: 1 November 2021

\begin{abstract}
Hysterosalpingography (HSG) is the most commonly used imaging diagnostic to determine the tubal patency in patient with indications of infertility. The technique used in the HSG procedure is different in some studies. The aim of this study was to determine the technique of hysterosalpingography (HSG) examination with patients suspected of infertility in Dr.R. Soetrasno Rembang hospital. The method was a case study approach. Results showed HSG examination using plain photo Anteroposterior (AP) projection, AP projection with 3 cc contrast media and 7 cc contrast media, then post evacuation. The AP projection already revealed uterus, fallopian tubes, spill on the peritoneum, reduce radiation dose, and the pain of patients. They used $3 \mathrm{cc}$ and $7 \mathrm{cc}$ of contrast media because the examination did not use fluoroscopy. The 3 cc of contrast media views the uterus only then $7 \mathrm{cc}$ view the fallopian tube and its spill. HSG plays a crucial role to determine the cause of infertility, especially to evaluate the morphology and patency of the fallopian tubes in women so the radiology team should become familiar with examination techniques used, give the patient education to avoid movement, and hold their body motionless also taking a mild pain reliever before the HSG examination.
\end{abstract}

Keywords: contrast media, hysterosalpingography, infertility, projection

\section{INTRODUCTION}

The female reproductive apparatus is divided into the outer reproductive apparatus (external) and the inner reproductive apparatus (internal). According to Manuaba (2007), the external reproductive apparatus consists of mons veneris (pubis), labia major, labia minor, clitoris, vestibulum, himen, vagina, perineum. While the internal reproductive apparatus according to (Anwar, 2011) includes the uterus, fallopian tubes, ovaries. Disorders common in the female reproductive system include primary sterility, secondary sterility, primary infertility, secondary infertility, neoplasm, salpingitis, pelvic inflammatory disease, and hydrosalpinges (Anwar, 2011).

A common disorder is an infertility. Infertility is the inability or decreased ability to produce offspring. Infertility in a couple can occur from the beginning of a relationship (primary infertility) or after the couple has one or more children (secondary infertility). 
Infertility is a disease defined by the failure to achieve a successful pregnancy after 12 months or more of regular, unprotected sexual intercourse or due to an impairment of a person's capacity to reproduce either as an individual or with her partner (Practice Committee of the American Society for Reproductive Medicine, 2020). Female factors that cause infertility can include problems related to follicle growth, structural abnormalities, fallopian tube blockage due to pelvic infection, or uterine abnormalities that can inhibit implantation (Pearce, 2013). Moreover, the cause of infertility because of tubal damage, ovulation disorder, or the combination of several factors. The imaging procedure become an important role in the diagnostic evaluation of female infertility (Schankath, 2012).

Actions that can be done to find out the cause of the disorder one of them by doing a hysterosalpingography (HSG) examination. HSG procedure provides an easy and inexpensive source for the evaluation of infertility factors (Sultana, 2018). HSG still remains the gold standard in the evaluation of tubal patency and uterine cavity abnormalities as well (Ahmed, 2019). HSG is a radiological procedure for looking at the shadow of the shape, position, and size of the uterine cavity and the fallopian tubes (Linder, 2019; Achuka 2020). HSG in infertility can be used to look at tubal patents and to evaluate the anomalies of the uterine cavity (Rasad, 2006; Maheux-Lacroix, 2019). HSG examination can be done by fluoroscopy or conventional X-ray using plain photos, post-contrast photos of anteroposterior projections (AP), and additional projections. Additional projections are oblique, axial, and lateral as a needed diagnosis on the examination as well as post evacuation photos after urinating (Frank, 2007). Additional projections of the right and left oblique are always used because they are able to reveal the entire anatomy of the reproductive organs (Bontrager, 2018). The contrast material that is often used is urography $60 \%$ of this contrast material is dilute (Rasad, 2006). Contrast media used on HSG inspection as much as $10 \mathrm{cc}$ for all inspection projections. A breakdown of $5 \mathrm{cc}$ for the anteroposterior projection (AP) aims to fill the uterine cavity while another $5 \mathrm{cc}$ for the right and left oblique projection aims to show the patenting of the tube (Bontrager, 2018).

The HSG examination technique used in the Radiology Installation of Dr. R. Soetrasno Rembang Hospital is a plain photo of AP projection, a photo of post-contrast AP projection, and a post evacuation photo after urinating with AP projection. The contrast media used is usually a mixture of $76 \%$ urography and aquabides with a ratio of $1: 2$ as much as $10 \mathrm{cc}$. Contrast media revenue is done by using a portubator, which is 3 cc for the first photo with AP projection and the second photo is included contrast again as much as $7 \mathrm{cc}$ using the same projection that is AP. This method differs from the study before commonly the procedure of HSG used some type of projection such as AP and oblique projection (Bontrager, 2018; Bushong, 2013). Also, the use of contrast a total of 5-20 ml of iodine water-based contrast (Maheux-Lacroix 2019). It is crucial to choose the contrast medium in the HSG examination. In spite of the fact that usually, they use just non-ionic water-soluble iodinated contrast media because of good radio-opacity, the absence of toxicity, good tolerability, and easy application but some prefer to use lipidsoluble contrast (Capobianco, 2021).

This study aims to examine the HSG examination techniques used in patients suspected of infertility at the Radiological Installation of dr.R. Soetrasno Rembang 
Hospital, reviewing the reasons why only using AP projections on HSG examinations and the use of contrast media of $3 \mathrm{cc}$ for the first photo and $7 \mathrm{cc}$ for the second photo on the HSG examination.

\section{RESEARCH METHODS}

The type of research used is qualitative with a case study approach. This research was conducted at the Radiology Installation of Dr. R. Soetrasno Rembang Hospital. The study subjects consisted of 2 radiologists, 2 radiographers, 1 patient, and 1 obstetrician. Method of retrieving data with observation, interview, and documentation. Data is collected through observations, in-depth interviews with radiographers, radiologists, and patients to obtain data related to this study, and documentation studies then the results are processed and analyzed with interactive models. The stages in data analysis with interactive models are data collection, data reduction, data presentation, and conclusions. Conclusion withdrawal is used to answer the problem formulation.

\section{RESULTS AND DISCUSSION}

HSG examination at the Radiology Installation of DR. R. Soetrasno Rembang is carried out on the $10^{\text {th }}$ day since the first day of the last period, the patient is prohibited coitus (spousal relationship) first during the preparation period (Bontrager, 2018; Bushong, 2013). The patient of childbearing age needs to determine that she is not pregnant to undergo this procedure (Linder, 2019). Then the patient changes clothes with examination clothes that have been provided in the examination room. The patient urinates first to empty the bladder so as not to interfere with the course of the examination and the results of the radiograph image later.

The preparation of tools and materials is divided into two, consisting of sterile and non-sterile tools. Sterile tools include HSG Set i.e., speculum, sonde uteri, clamps, portio tang, portubator, and conus as well as crooked, sterile bowl, spuit $10 \mathrm{ml}$, cotton / sterile gauze, handscoon, and povidone iodine as well. Non-sterile tools include X-ray aircraft, cassettes, and films measuring $24 \times 30 \mathrm{~cm}$, markers, grids, gynecological lamps, jelly/vaseline, apron, and processing film (Bontrager, 2018). Contrast media used iodine water-soluble with the trademark urography $76 \%$ mixed with aquabides / RL as much as $10 \mathrm{cc}$ with a ratio of 1: $2.10 \mathrm{ml}$ of contras media is usually sufficient to fill the uterus, both fallopian tubes, and demonstrate spillage of contrast into the peritoneum bilaterally if both fallopian tubes are open and patent (Bontrager, 2018).

The examination technique used is to use conventional X-ray by doing plain photos of AP projections, photo post-contrast AP projections, and finally photos post evacuation after urinating. The addition of contrasting media is done by the radiologist. Supine patient with lithotomy position. A radiologist cleans the area around the external genitalia with an aseptic technique that is disinfected in the vaginal canal, then inserts the speculum slowly to open the uterine pathway. After that, the radiologist inserts the sonde uteri to find out the depth of the uterus and the direction of the uterus. The speculum is fixated with the cervix part disinfected again using povidone iodine and the radiologist pairs the installed $10 \mathrm{cc}$ spuit portubator with contrast media. The result of the image HSG examination is shown in Figures 1-4. 


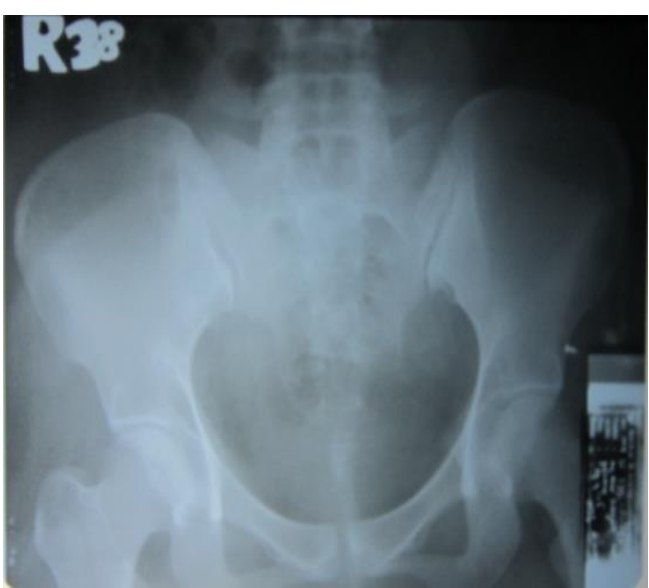

Figure 1. Plain photo of AP projection ( Dr.R. Soetrasno Rembang Hospital )

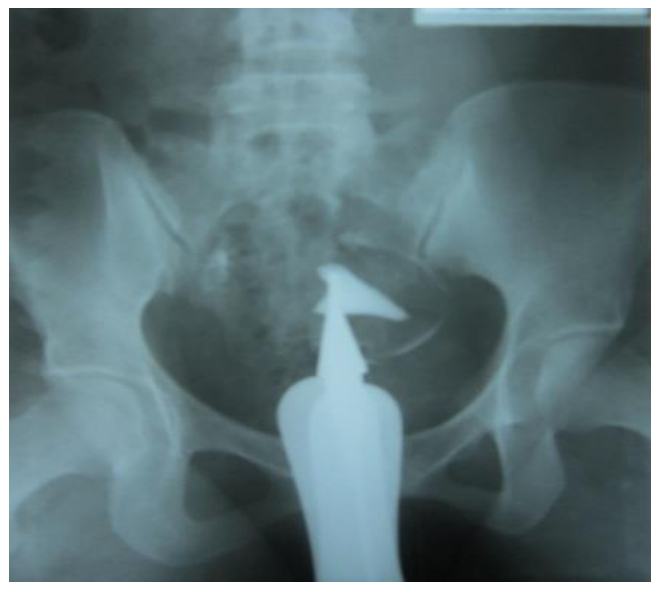

Figure 3. Photo of AP post contrast of $7 \mathrm{cc}$ patient Dr.R. Soetrasno Rembang Hospital)

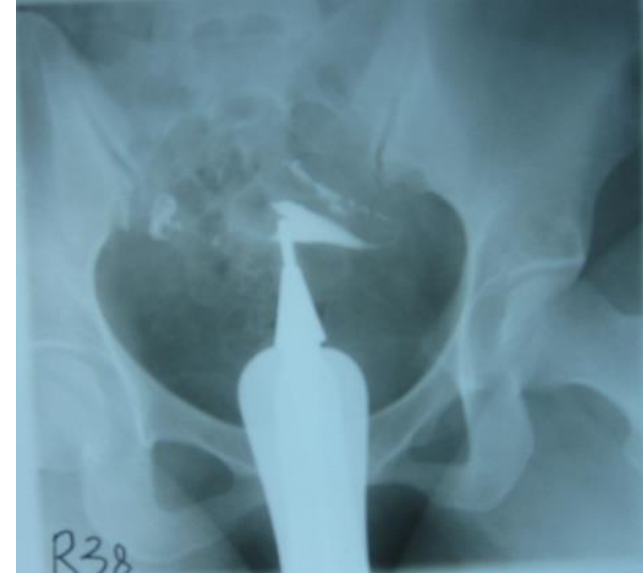

Figure 2. Photo of AP Post contrast of $3 \mathrm{cc}$ Patient ( Dr.R. Soetrasno Rembang Hospital)

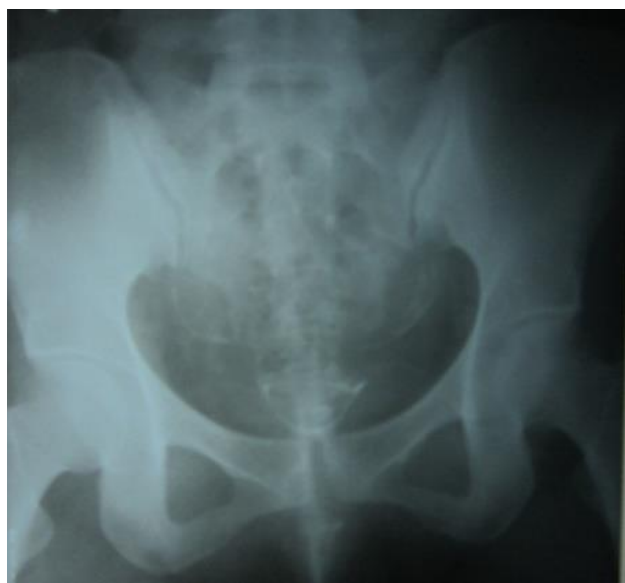

Figure 4. Photo of Post Evacuation Patient (Dr.R. Soetrasno Rembang Hospital)

The reason is only to use AP projections only on the technique of examination of Hysterosalpingography on suspected infertility in radiological installations of Dr. R. Soetrasno Rembang Hospital is because by using AP projection has been able to show the uterus and fallopian tubes and has appeared spill on the right and left peritoneum. In addition, if only using AP projections can already show spill, then there is no need to add with oblique projection because it can add radiation and also pain in patients due to too long HSG examination. According to the theory in HSG examination in radiology installation Dr. R. Soetrasno Rembang hospital should use additional projections such as right and left oblique projections (Bontrager, 2018). This can be done if the radiologist is not sure about the results of the radiograph that only uses AP projections while still looking suspicious in the right and left fallopian areas. Oblique projections can show the entire anatomy and patent of the fallopian tubes. These additional projections can be done situationally according to the needs of the radiologist in order to help in enforcing the diagnosis (Schankath, 2012).

The procedure of HSG commonly used fluoroscopy but if fluoroscopy is not used, a spot image of radiograph could be taken after each projection and injection of contrast to demonstrate tuba filling, uterine filling, and spillage of contrast into peritoneum (Linder, 2019). In dr. R. Soetrasno Rembang Hospital the reason for the inclusion of contrast media $3 \mathrm{cc}$ for the first photo and $7 \mathrm{cc}$ for the second photo is because the HSG 
examination does not use fluoroscopy then the contrast media inserted is $3 \mathrm{cc}$ first to see the uterus only, because if directly inserting contrast media with more volume, then contrast media can enter the uterus and fallopian tubes. In addition, it is also to see the patient's reaction to the contrast media included. Then inserted a contrast media as much as $7 \mathrm{cc}$ with the aim to see the fallopian tube and its spill. This is slightly different according to Bontrager (2018) for contrast media injection should be $5 \mathrm{cc}$ for AP projection while another $5 \mathrm{cc}$ for right oblique or left oblique. Because the shape of the uterus of each person is different such as anteflexion or retroflexion is not all the same so if the volume of contrast media entered only $3 \mathrm{cc}$ for the first photo is not necessarily enough to fill the entire uterine cavity of the patient. For the second photo, the volume entered is also quite $5 \mathrm{cc}$ only because to show the spill, so that it can be clearly seen.

HSG plays a crucial role to determine the cause of infertility, especially to evaluate the morphology and patency of the fallopian tubes in women. HSG also has therapeutic effects (Gündüz, 2021). Morevover increases the ongoing pregnancy rate of couples with unexplained infertility compared with no HSG, regardless of the contrast medium used (Dreyer, 2019). However, is painful and may cause intense cramping sensations because of contrast injection. So, the radiology team should become familiar with examination techniques used, give the patient education to avoid movement, and hold their body motionless also may advise taking a mild pain reliever before the HSG examination (Linder, 2019). Some of the studies used a different procedure to decrease the pitfall of HSG they are performed hysterosalpingosonography (Sono-HSG) or HSGMRI but further study might be needed to determine the best examination for women infertility (Lee, 2017; Schankath, 2012; Chen, 2020). In Indonesia, HSG is still the most commonly used diagnostic method in patients with infertility. HSG become a useful diagnostic tool for patients with infertility that has therapeutic effects on fertility success (Al-Jaroudi, 2018; Sanei, 2020).

\section{CONCLUSION}

The procedure of examination of Hysterosalpingography (HSG) on suspected infertility in the Radiology Installation of Dr.R. Soetrasno Rembang Hospital requires special preparation in the form of counting the first day of the last period (HPHT). The examination is carried out on the 10th day since the calculation of HPHT and also the patient does not do coitus (spousal relationship). The examination technique uses a plain photo of AnteroPosterior projection (AP), an AP projection post photo with 3 cc contrast media volume, an AP projection contrast post photo with $7 \mathrm{cc}$ contrast media volume, and post evacuation photo after urinating. The reason used only AP projection is because it can show the uterus, fallopian tubes and appear spill on the right and left peritoneum. Furthermore, is to reduce radiation doses as well as pain in patients. The HSG examination does not use fluoroscopy so the contrast media inserted as much as $3 \mathrm{cc}$ first to see the uterus clearly and see the patient's reaction to the contrast media inserted. Then the inclusion of contrast media as much as $7 \mathrm{cc}$ aims to see the fallopian tube and its spill. 


\section{REFERENCES}

Achuka, J. A., Aweda, M. A., Usikalu, M. R., \& Aborisade, C. A. (2020). Assessment of patient absorbed radiation dose during hysterosalpingography: A pilot study in Southwest Nigeria. Journal of Biomedical Physics \& Engineering, 10(2), 131.

Ahmed, S. A., \& Taleb, H. A. (2019). Diagnostic Efficiency and Reproducibility of Hysterosalpingography. Int J Radiol Imaging Technol, 5, 051.

Al-Jaroudi, D., Aldughayyim, A. A., Alshamry, W. S., Alrashidi, A. S., \& Bahnassy, A. A. (2018). Hysterosalpingogram findings among subfertile women undergoing assisted reproductive technology. International journal of women's health, 10, 431.

Anwar, Mochamad.(2011).Ilmu Kandungan, Edisi 3,Cetakan 1. PT Bina Pustaka Sarwono Prawiroharjo : Jakarta.

Bontrager, Kenneth, L. (2018). Tex Book of Radiographic Positioning and Related Anatomy, Seventh Edition. Mosby Inc, St. Louis : Amerika.

Bushong, S. C. (2013). Radiologic Science for Technologists E-Book: Physics, Biology, and Protection. Elsevier Health Sciences.

Capobianco, G., Crivelli, P., Piredda, N., Maiore, M., Cherchi, P. L., Dessole, M., ... \& Meloni, G. B. (2021). Hysterosalpingography in infertility investigation protocol: is it still useful? Clinical and experimental obstetrics \& gynecology, 42(4), 448451.

Chen, L. S., Zhu, Z. Q., Li, J., Wang, Z. T., Qiang, Y., Hu, X. Y., \& Wang, Z. Q. (2020). Hysterosalpingo-contrast-sonography vs. magnetic resonancehysterosalpingography for diagnosing fallopian tubal patency: A systematic review and meta-analysis. European journal of radiology, 125, 108891.

Dreyer, K., van Eekelen, R., Tjon-Kon-Fat, R. I., van der Steeg, J. W., Steures, P., Eijkemans, M. J. C., \& van Geloven, N. (2019). The therapeutic effect of hysterosalpingography in couples with unexplained subfertility: a post-hoc analysis of a prospective multi-centre cohort study. Reproductive biomedicine online, 38(2), 233-239.

Frank E.D.(2007). Merrill's Atlas of Radiographic Positioning and Radiologic Prosedures, Volume Two, Eleventh Edition. The VC Mosby co : London

Gündüz, R., Ağaçayak, E., Okutucu, G., Karuserci, Ö. K., Peker, N., Çetinçakmak, M. G., \& Gül, T. (2021). Hysterosalpingography: a potential alternative to laparoscopy in the evaluation of tubal obstruction in infertile patients?. African Health Sciences, 21(1), 373-8.

Lee, F. K., Lee, W. L., \& Wang, P. H. (2017). Is hysterosalpingography a good tool to confirm the patency of tubes?.

Linder, J. M. B. (2019). Hysterosalpingography in an Infertile Woman: Case Study and Clinical Considerations. Journal of Radiology Nursing, 38(1), 53-55.

Manuaba Ida Bagus G.(2007). Pengantar Kuliah Obstetri. EGC: Jakarta 
Maheux-Lacroix, S., Bergeron, C., Moore, L., Bergeron, M. È., Lefebvre, J., GrenierOuellette, I., \& Dodin, S. (2019). Hysterosalpingosonography is not as effective as hysterosalpingography to increase chances of pregnancy. Journal of Obstetrics and Gynaecology Canada, 41(5), 593-598.

Pearce, Evelyn C.(2013). Anatomi dan Fisiologi untuk Paramedis, Cetakan XL. Prima Grafika: Jakarta

Practice Committee of the American Society for Reproductive Medicine. (2020). Definitions of infertility and recurrent pregnancy loss: a committee opinion. Fertility and sterility, 113(3), 533-535.

Rasad, Sjahriar.(2006). Radiologi Diagnostik, Edisi Kedua.Gaya Baru Balai Penerbit FKUI : Jakarta

Sanei Sistani, S., Dahmardeh, H., Hasanzadeh, R., \& Farzaneh, F. (2020). Effect of Hysterosalpingography (HSG) on Biochemical Pregnancy Rate in Women with Primary and Secondary Infertility. Zahedan Journal of Research in Medical Sciences, 22(4).

Sultana, B. U. S. H. R. A., Ashraf, A., Noon, S., Faiz, H. A. M., \& Yousaf, I. (2018). Hysterosalpingography (HSG) for Evaluation of Primary Infertility in Females. Pakistan Journal of Medical and Health Sciences, 12, 1077-1078.

Schankath, A. C., Fasching, N., Urech-Ruh, C., Hohl, M. K., \& Kubik-Huch, R. A. (2012). Hysterosalpingography in the workup of female infertility: indications, technique and diagnostic findings. Insights into imaging, 3(5), 475-483. 